\title{
As origens do movimento latino-americano de história das ideias
}

\author{
The origins of the Latin American history of \\ ideas movement
}

Eugênio Rezende de Carvalho*

Resumo: O artigo explora comparativamente as contribuições do filósofo espanhol exilado no México, José Gaos (1900-1969), e do filósofo argentino de origem espanhola, Francisco Romero (1891-1962), para a constituição do movimento intelectual latino-americano de história das ideias, em torno de 1940. Pretende-se demonstrar como ambos os filósofos dariam início, de forma independente e paralela, a um amplo e intenso trabalho de produção, organização, orientação, incentivo e difusão dos estudos de história das ideias, inicialmente restrito ao âmbito de seus respectivos países.

Palavras-chave: História das ideias latino-americanas. José Gaos. Francisco Romero.

Abstract: The article intends to analyse comparatively contributions from the Spanish philosopher exiled in Mexico, José Gaos (1900-1969), and also from the Argentinian philosopher of Spanish origin, Francisco Romero (1891-1962), to establish the intellectual movement of the Latin-American history of ideas, around 1940. It is intended to reveal how both philosophers would initiate, independently and in parallel way, a large and intense work of production, organization, guidance, support and dissemination regarded to the studies of history of ideas, initially restricted to the extent of their respective countries.

Keywords: Latin American history of ideas. José Gaos. Francisco Romero.

* Doutor em História Social e das Ideias pela Universidade de Brasília (UnB) e professor da Universidade Federal de Goiás (UFG), onde exerce a docência e desenvolve pesquisas na área de História Latino-americana. É bolsista produtividade em pesquisa do CNPq. É autor dos livros Nossa América: a utopia de um novo mundo (São Paulo: Anita Garibaldi, 2001), América para a humanidade: o americanismo universalista de José Martí (Goiânia: Ed. UFG, 2003) e Pensadores da América Latina o movimento latino-americano de história das ideias (Goiânia: Ed. UFG, 2009). <eugeniodecarvalho@gmail.com>. 
Nas décadas de 1940 e 1950, um grupo representativo de intelectuais latino-americanos e caribenhos de diferentes nacionalidades, constituído basicamente por filósofos, deu início a uma vigorosa corrente de reflexão e estudos sobre a história do pensamento latino-americano no período pós-independência, bem como sobre aquelas que seriam as características essenciais e originais desse pensamento. Fundaram, assim, uma vertente peculiar da história das ideias na América Latina.

$\mathrm{Na}$ verdade, para além de uma mera corrente ou vertente particular da história das ideias, tratou-se mesmo de um movimento - como doravante passaremos a denominá-lo -, organizado e articulado por esses pensadores de meados do século XX, que associou o seu projeto de uma história das ideias latino-americana a uma perspectiva de autoafirmação nacional e continental. Entre outras atividades, tal movimento fundou destacadas organizações e instituições - dentro e fora dos meios universitários-, produziu e incentivou um número significativo de eventos e de publicações, sempre com o propósito de promover o intercâmbio e a articulação dos inúmeros investigadores que atuavam na área da história das ideias na América Latina. Mas, também, um movimento que, por outro lado, utilizando desses meios, procurou sugerir e implementar um determinado programa de orientação dos estudos latino-americanos no campo das ideias, segundo certos pressupostos teóricos, metodológicos, filosóficos e epistemológicos relativamente claros. Entre os principais representantes desse movimento destacaram-se o mexicano Leopoldo Zea Aguilar (1912-2004) - sem dúvida, a principal referência do grupo -, o uruguaio Arturo Ardao (1912-2000) e o argentino Arturo Andrés Roig (1922-).

Este artigo pretende explorar o contexto intelectual e filosófico de emergência desse movimento, procurando analisar, a partir de uma perspectiva mais geral, o processo de constituição de seus dois focos principais, situados no México e na Argentina, liderados respectivamente pelos filósofos José Gaos (1900-1969) e Francisco Romero (1891-1962), considerando tal análise fundamental para a compreensão da natureza e da trajetória posterior desse movimento intelectual como um todo.

\section{$O$ contexto intelectual e filosófico de emergência do movimento}

Para a compreensão da gênese e trajetória do movimento latinoamericano de história das ideias, há que se considerar, antes de tudo, a sua origem e natureza eminentemente filosóficas, embora dentro de uma 
concepção muito particular de filosofia assumida por seus representantes. Assim, é preciso situar a emergência de tal movimento, em princípios da década de 1940, em meio ao grande impulso da filosofia na América Latina.

Um de seus principais integrantes, o filósofo uruguaio Arturo Ardao, considerou que naquela época houve, ao lado de uma progressiva intensificação dos estudos filosóficos, uma abertura a novas tendências doutrinárias e disciplinares (tais como a filosofia da cultura, a filosofia dos valores e a antropologia filosófica). Mas teria havido, sobretudo, a consolidação de uma consciência filosófica latino-americana que incorporava e valorizava a autorreflexão sobre a própria produção filosófica continental (Ardao, 1991, p. XI). Em tal contexto, o pensamento filosófico latino-americano colocou em questão as suas relações com a filosofia e a cultura europeias. É precisamente nesse cenário intelectual de consolidação de uma consciência filosófica latino-americana, bem como de uma intensa autorreflexão sobre a produção filosófica local, que emergiu o movimento de história das ideias na América Latina.

Como parte desse processo - funcionando como pano de fundo, como um fator externo decisivo para o surgimento do movimento, interpelando e inquietando seus iniciadores e promotores -, encontrava-se uma velha polêmica bastante recorrente entre a intelectualidade hispanoamericana, desde meados do século XIX. Tratava-se da tendência de se opor o caráter "importado" ao caráter "autóctone" do pensamento e da produção intelectual latino-americana, em busca de especificidades, nacionais ou latino-americanas, frente ao pensamento europeu ${ }^{1}$. Nesse sentido, a história das ideias filosóficas era uma história, no dizer de seus representantes, de suas próprias ideias, ou seja, daquelas que foram assimiladas externamente (da matriz filosófica europeia ou ocidental) pelos intelectuais latino-americanos e adaptadas à sua própria realidade. Em suma, tratava-se de uma história das ideias entendidas já como ideias latino-americanas.

Sobre esse ponto, em meados do século XIX, foi decisiva a polêmica levantada pelo pensador argentino Juan Bautista Alberdi (1810-1884) sobre a existência de uma filosofia americana. No ensaio intitulado Ideas para presidir a la confección del curso de filosofía contemporánea, lido no Colégio de Humanidades de Montevidéu, em 1842, Alberdi declarou não haver uma filosofia universal, porque não existia, no fundo, uma solução universal para as questões que a constituem. A filosofia seria

\footnotetext{
${ }^{1}$ Cf. Strozzi, 1999, p. 8.
} 
única em seus elementos fundamentais, como a humanidade, mas diversa em suas aplicações nacionais e temporais. Nessa perspectiva, cada país, cada época e cada filósofo teriam a sua filosofia peculiar, desde que apresentassem soluções distintas para os problemas do espírito humano. $\mathrm{E}$ assim como havia uma filosofia oriental, uma grega, uma romana, uma alemã, uma inglesa e uma francesa, era necessário que houvesse também uma filosofia americana, para resolver "o problema dos destinos americanos" (Alberdi, 1842, p. 1-2 e 6).

Posteriormente, a tese de Alberdi foi continuamente retomada por vários intelectuais e filósofos latino-americanos ${ }^{2}$ e, com maior vigor, a partir das décadas de 1940 e 1950, no contexto da Segunda Guerra Mundial, pelos representantes e teóricos do movimento latinoamericano de história das ideias, particularmente por Leopoldo Zea ${ }^{3}$. Segundo o investigador Horacio Cerutti Guldberg, teria surgido nesse momento uma tradição de pensamento na América Latina que se autoproclamaria continuadora da tradição do historicismo romântico, iniciada principalmente por Alberdi. "A primera vista y de modo quizá superficial, pareciera constituirse en el correlato del proceso de sustitución de importaciones a nivel de la expresión máxima de la cultura, el momento de la autoconciencia: la filosofía." (Cerutti Guldberg, 1997, p. 184).

Tal reação deve ser compreendida no contexto mais amplo de afirmação crescente, no seio do grupo, de uma consciência e indignação frente ao que o historiador italiano das ideias Antonello Gerbi (19041976) chamou de "calúnia" contra a América. Em seu clássico livro dos anos 60, O Novo Mundo: história de uma polêmica (1750-1900), Gerbi apresentou, com profunda erudição, as raízes e a trajetória da tese da inferioridade das Américas, que abrange sua natureza e sua gente. Para tal, baseou-se na polêmica iniciada em meados do

2 Arturo Andrés Roig, por exemplo, ressaltou a influência direta dos escritos de Alberdi sobre dois dos mais importantes filósofos precursores da História das Ideias na Argentina do início do século XX, José Ingenieros e Alejandro Korn, que se consideravam abertamente herdeiros de Alberdi (Roig, 1984, p. IV). No caso de Ingenieros, o postulado alberdiano já estaria presente no primeiro esboço de sua obra La evolución de las ideas argentinas (1914). No caso de Korn, já nos seus primeiros escritos para a Revista de la Universidad de Buenos Aires e, de forma mais clara nos textos Nuevas bases (1925) e Filosofía argentina (1927). Este último, mais do que reconhecer a pré-existência de uma filosofia argentina desde a época de Alberdi, se propunha a revigorá-la e renová-la, tarefa a qual se dedicou posteriormente até o final de sua vida (Ardao, 1992, p. 227).

3 Para quem tal preocupação de Alberdi teria surgido "de la búsqueda de solución a los problemas que se plantean en esta región de la tierra a partir de soluciones que a problemas semejantes diera el filosofar europeo y occidental" (Zea, 2000, p. 39). 
século XVIII pelo naturalista francês Conde de Buffon (1707-1788) e pelo abade prussiano Corneille De Pauw (1739-1799). Gerbi investigou os inúmeros argumentos utilizados pelos contendores, na maior parte carregados de preconceitos de ordem teológica, biológica, histórica, científica ou pseudocientífica. Imaturidade, impotência, inferioridade e degeneração foram alguns dos termos mais recorrentes que povoaram, durante séculos, essas acaloradas descrições da realidade americana analisadas por Gerbi ${ }^{4}$.

Convém observar aqui não só como, em meados do século $\mathrm{XX}$, os principais líderes do movimento latino-americano de história das ideias reagiram às imagens e às descrições negativas da realidade e dos habitantes da América, mas também que relações a tese da inferioridade - e suas variantes e atualizações - guardaria com a já aludida formação, nesse momento, de uma consciência filosófica latino-americana que valorizava a autorreflexão sobre a sua própria produção filosófica.

Ao analisar os escritos de alguns dos principais representantes do movimento, percebe-se que eles se propuseram, consciente e expressamente, a dar continuidade à obra de Gerbi ${ }^{5}$. É o caso de Arturo Andrés Roig que, ao destacar a importância da obra de Gerbi para a história das ideias latino-americanas, afirmou tratar-se de uma "obra que por nuestra parte hemos tratado de continuar y enriquecer ya que su autor nos la dejó generosamente abierta" (Roig, 1984, p. XVII). O propósito do grupo era, acima de tudo, superar tal complexo de inferioridade, impotência, incapacidade e inumanidade que havia sido forjado durante séculos e que ainda se mantinha de certa forma vigente, em pleno século $\mathrm{XX}$, nos meios intelectuais latino-americanos. A propósito, Leopoldo Zea escreveu:

La pregunta sobre la originalidad, el sentimiento de inferioridad y otras expresiones de las reflexiones del hombre de esta parte del mundo no era sino expresión de una realidad que, al hacerse consciente, mostrarían a otros hombres una situación, un punto de partida de un reflexionar distinto, pero no por ello menos filosófico, menos expresión de lo humano por excelencia... (Zea, 2000, p. 26).

4 Antonello Gerbi manteve, desde o início do movimento, uma relação direta e estreita com o grupo latino-americano de historiadores das ideias, participando de eventos e publicando em periódicos e coletâneas editados por esse grupo.

5 Como Gerbi deixou inacabada a sua obra sobre a trajetória da tese da inferioridade das Américas, já que limitou cronologicamente sua análise ao ano de 1900, ele mesmo reconheceu que novos personagens e novos termos poderiam ser acrescentados na polêmica iniciada no século XVIII (Gerbi, 1996). 
Assim, consciência e indignação frente a tal complexo de inferioridade, bem como o empenho em superá-lo por meio do reconhecimento e da afirmação da capacidade de um pensamento latino-americano autóctone, distinto e original, parecem ter sido as preocupações básicas dos representantes do movimento e que marcaram o contexto intelectual de sua emergência. Tratava-se de um momento em que a reflexão filosófica na América Latina tendia a voltar-se criticamente para si mesma, num autoquestionamento. Em suma, era um contexto marcado pela interrogação acerca da possibilidade de uma autêntica filosofia latino-americana. Isso porque, "en nuestros países la filosofía parece tener todos los rasgos de la inautenticidad: falta de originalidad, superficialidad, carencia de continuidad y, sobre todo, dependencia imitativa de la producción filosófica de otros países" (Villoro, 1993, p. 183).

Ainda, segundo Villoro, adquirir consciência de tal situação e propor vias para superá-la foi a grande obra de vários intelectuais e filósofos latino-americanos. Tal debate sobre a autenticidade e a originalidade da reflexão filosófica americana e latino-americana, de remotas origens, ganharia um novo impulso com a polêmica travada em 1968-1969 entre Zea e o filósofo peruano Augusto Salazar Bondy (1925-1974), de grande impacto para o movimento de história das ideias na região.

Ao criticar o caráter universalista abstrato assumido pela filosofia ocidental de matriz europeia, Zea procurava legitimar a filosofia latinoamericana enquanto tal. Para ele, estudar a obra dos pensadores latinoamericanos e investigar como eles tentaram captar a sua própria realidade social e histórica, visando à solução de seus problemas concretos, já era fazer filosofia. Em suma, foi exatamente esse modo peculiar de entender a filosofia que marcou a relação que o movimento estabeleceu entre a história da filosofia e a história das ideias, ao fazer com que a história de sua filosofia (latino-americana) fosse compreendida como história das ideias, e não como a tradicional e acadêmica "história da filosofia" (Roig, 1994, t. II, p. 128).

Como a disciplina história das ideias se desenvolveu na América Latina privilegiando o estudo das ideias filosóficas (embora dentro de uma concepção restrita de filosofia) ${ }^{6}$, alguns autores consideram que, de forma geral, as denominações história das ideias e história das ideias filosóficas tendem mesmo a se sobrepor ou a se identificar,

Não obstante ter sido realizada majoritariamente por filósofos, essa vertente da história das ideias na América Latina não se identificou com uma história das ideias restrita ao estudo do pensamento sistemático, ou seja, das ideias geralmente expostas em tratados filosóficos, conforme a tipologia de Robert Darnton (1990, p. 188). 
referindo-se ambas a mesma atividade historiográfica. Essa é a posição assumida, entre outros, pelos mexicanos Horacio Cerutti Guldberg e Mario Magallón Anaya, para quem falar de filosofia latino-americana era algo praticamente inseparável das referências à história das ideias (Cerutti Guldberg; Magallón Anaya, 2003, p. 36). Tais identificações - entre filosofia latino-americana, história das ideias e história das ideias filosóficas ou história da filosofia -, obviamente, se relacionam intimamente com o debate inaugurado por Alberdi acerca da existência de uma filosofia americana.

Por fim, no que diz respeito às influências filosóficas atuantes sobre o movimento latino-americano de história das ideias, que marcaram o contexto intelectual e filosófico de sua fundação e desenvolvimento, há que se considerar a forte presença do historicismo nas vertentes filosóficas do espanhol Ortega y Gasset e do alemão Wilhelm Dilthey. Um balanço importante dessas influências pode ser encontrado em vários textos de Zea, para quem a filosofia europeia se converteu em um instrumento a serviço da tomada de consciência da realidade americana, na medida em que o filósofo e o historiador fizeram dessa filosofia um instrumento de busca de sua realidade. Foi o caso da filosofia alemã, ou da influência de Ortega y Gasset, que estimularam esses primeiros trabalhos de reflexão a partir da década de $1920^{7}$ (Zea, 1991, p. 153). Para esse filósofo mexicano, foi precisamente Ortega - com sua ênfase na historicidade e limitação de toda filosofia - que teria aberto as portas do historicismo para a filosofia latino-americana, dando ao latinoamericano consciência dos alcances e possibilidades de seu filosofar (Zea, 1993a, p. 91).

No caso do historicismo de Dilthey, Leopoldo Zea destacou a sua contribuição metodológica (método compreensivo) para a formação da história das ideias na América Latina, na medida em que inspirou e influenciou as obras mestras produzidas nesse campo de estudos. (Zea, 1972, p. 17). Nessa perspectiva, segundo esse autor, a história das

7 De acordo com Leopoldo Zea, a partir de Ortega - por meio de sua própria obra, das suas traduções de vários clássicos da filosofia e também de outros textos divulgados na sua Revista de Occidente -, teriam chegado à América as doutrinas que justificavam e davam qualidade filosófica à meditação sobre a realidade americana (Zea, 1991, p. 76). Contribuindo para a renovação e a intensificação do debate filosófico, a difusão dessas novas perspectivas filosóficas foram facilitadas pelas iniciativas do Fondo de Cultura Económica (México) e da Editorial Losada (Argentina), além de outras editoras latinoamericanas, que passaram a publicar, desde a primeira metade do século XX, traduções em espanhol de autores como Wilhelm Dilthey, Werner Jaeger, Ernest Cassirer, Edmund Husserl, Martin Heidegger, entre outros (Zea, 1993b, p. 94-95). 
ideias seria o campo em que o historicismo foi aplicado para o melhor conhecimento da América Latina. Dilthey, Ortega, Scheler, Mannheim e, mais recentemente, Toynbee viriam a formar o instrumento mais idôneo com que o estudioso das ideias na América vinha enfrentando a sua história, para captar nela o sentido dessas ideias em relação com a realidade dentro da qual surgiram (Zea, 1991, p. 154). A essa corrente historicista, como seu complemento, somar-se-ia mais tarde a corrente existencialista e antropológica de Heidegger e Sartre, reforçando o instrumental metodológico de conhecimento da realidade americana e, em particular, das expressões de seu pensamento.

Em suma, a emergência do movimento de história das ideias na América Latina pode ser situada na década de 1940, no contexto intelectual marcado por um acalorado debate filosófico. Sob a égide e a influência do historicismo, o impulso alcançado pelos estudos filosóficos na América Latina nesse período esteve vinculado à consolidação de uma consciência filosófica latino-americana que valorizou a reflexão sobre a sua própria produção intelectual na relação com as matrizes do pensamento filosófico europeu. Tal consciência filosófica esteve, por sua vez, acompanhada de um modo peculiar de entender a filosofia, como reflexão sobre os problemas concretos do contexto específico de quem a produz, em contraposição à concepção universalista abstrata preponderante na matriz filosófica europeia.

Partindo de uma peculiar definição de filosofia, os integrantes do movimento latino-americano de história das ideias passaram a defender não apenas a simples existência, mas também o caráter original e legítimo de uma filosofia latino-americana, forjando uma consciência filosófica apoiada na elevação da autoestima e na valorização do próprio, repelindo qualquer tese de inferioridade. Considerando o pressuposto da existência dessa peculiar filosofia latino-americana, ela poderia então ser historiada, e o objeto de tal história consistiria nas ideias expressas pelos pensadores - no caso, latino-americanos -, no processo de reflexão sobre a sua própria realidade social e histórica, com o propósito de apreendê-la e de dar solução aos seus problemas concretos.

\section{A formação do foco mexicano: a contribuição pioneira de José Gaos}

A Guerra Civil Espanhola (1936-1939) e seus desdobramentos foram decisivos para o surgimento do movimento da história das ideias na América Latina, pois, com a derrota republicana no conflito, 
intelectuais espanhóis buscaram refúgio em diversos países hispanoamericanos. Um grupo desses exilados se dirigiu à capital do México, em 1938, quando foram recebidos pelo então presidente Lázaro Cárdenas na recém-fundada Casa de España no México, que foi transformada em 1940 no Colegio de México. Fazia parte desse grupo o filósofo José Gaos, ex-reitor da Universidade de Madri, que havia aceitado o convite de dois importantes acadêmicos mexicanos, Alfonso Reyes e Daniel Cossío Villegas, para integrar-se à Casa de España.

Em 1940, José Gaos organiza no Colegio de México um seminário "para o estudo do pensamento nos países de língua espanhola", em convênio com a Faculdade de Filosofia e Letras da Universidade Autônoma do México (UNAM). Gaos pretendia, nesse Seminário, analisar as obras mestras da história do pensamento mexicano, considerando que os mexicanos chegariam a formular um pensamento original baseado no conhecimento e na reflexão sobre o seu próprio passado filosófico. Com base em tal pressuposto, ele promoveu os estudos de história das ideias, num primeiro momento no México e, posteriormente, no âmbito mais geral da Hispano-América. É óbvio que esse novo campo do saber exigia uma prévia definição dos sentidos e alcances, bem como de suas relações com a tradicional história da filosofia, que era igualmente objeto de atenção dos participantes do Seminário (Roig, 1984, p. II).

A preocupação de Gaos pelo estudo da história das ideias ou do pensamento na Hispano-América deve ser compreendida em função da presença - em sua formação e bagagem filosófica - de certas vertentes do historicismo e, sobretudo, das ideias de Ortega y Gasset. Quando era estudante na Faculdade de Filosofia e Letras da então Universidade Central de Madri, Gaos estabeleceu um estreito convívio filosófico com o seu então mestre Ortega, de quem iria assimilar uma série de princípios filosóficos, dentre os quais a tese do circunstancialismo histórico ${ }^{8}$, da qual se tornou um dos principais defensores e difusores na HispanoAmérica. Para Ortega, a ideia - que não é portadora de um conteúdo ou de um sentido em si mesma - é uma ação que o indivíduo realiza, em uma determinada circunstância e com uma finalidade precisa, de tal maneira que tal circunstância e tal finalidade são imprescindíveis para a compreensão dessa ideia.

Em um estudo sobre o legado das ideias de Ortega y Gasset na América Latina, através principalmente de Gaos e das suas influências no interior do movimento da história das ideias latino-americanas, Santamaría García (1993) analisa especificamente esse circunstancialismo histórico orteguiano. 
Nessa perspectiva, não há ideias eternas, já que toda ideia estaria subordinada à circunstância específica na qual exerce uma determinada função. É mediante a incorporação dessa tese orteguiana do circunstancialismo histórico que, a partir de sua chegada ao México, Gaos lança as bases de uma história das ideias como uma disciplina autônoma - em substituição à história da filosofia tradicional-, valorizando o estudo e a originalidade de certas categorias filosóficas emanadas da realidade cultural hispano-americana e reproduzidas nas obras de seus pensadores.

Por outro lado, o legado filosófico de Ortega ofereceu a Gaos a possibilidade de uma filosofia útil à vida e a um desenvolvimento nacional que buscasse suas raízes na própria história e na própria tradição intelectual, sem menosprezar as contribuições exteriores. Por meio desse legado filosófico, o intelectual encontrava seu papel não somente na reflexão latino-americana sobre si mesma, mas também na elaboração de um pensamento útil para a realidade social em que se encontrava (Santamaría García, 1993, p. 305). Foi com essa dupla finalidade que Gaos fundou e dirigiu os seus seminários no Colegio de México, onde, sob a sua orientação, se formaram diversos pensadores mexicanos, alguns de grande importância no desenvolvimento posterior do movimento da história das ideias, como é o caso de Leopoldo Zea.

Ao abordar a significativa contribuição de Gaos, Zea considerou que a história das ideias era a história de como os pensadores latino-americanos foram recebendo e assimilando as expressões da filosofia europeia (escolástica, racionalismo, ilustração, positivismo, espiritualismo, historicismo e existencialismo). O sentido da almejada peculiaridade do pensamento ou filosofia latino-americana, tão amplamente defendida por Gaos, residiria precisamente na transformação de tais expressões filosóficas em instrumentos originais para a solução dos problemas específicos da realidade latino-americana (Zea, 2000, p. 39-40).

As linhas gerais da posição filosófica de Gaos, cristalizada em sua experiência com a nova realidade histórica hispano-americana, aparecem já de modo incipiente em suas primeiras conferências e, de forma mais sistemática, a partir de 1939, quando formula suas teses centrais de uma "filosofia da filosofia". Essa filosofia da filosofia de Gaos não consistia em uma nova disciplina filosófica, mas apenas no resultado da atividade de autorreflexão do filósofo, que surge quando ele se coloca como um

${ }_{9}^{9}$ Cf. Gómez-Martínez, 1991, p. 58. Sobre o tema Gaos publicaria mais tarde, em 1947, o livro Filosofia de la filosofía e historia de la filosofia. 
indivíduo concreto. Em seu projeto de estudar o passado filosófico iberoamericano, como passo prévio para o reconhecimento da sua existência, ele dedicou-se às primeiras leituras sobre a produção filosófica do México daquela época, quando então descobriu a originalidade das obras de alguns filósofos mexicanos contemporâneos a ele.

Mas foi a leitura, ainda em 1938, do livro El perfil del hombre y la cultura en México (1934), do filósofo mexicano Samuel Ramos (18971959), que mais chamou a atenção de Gaos. Conforme expressou em uma resenha publicada em 1939, ele percebeu uma grande semelhança entre essa obra e as Meditaciones del Quijote, de Ortega y Gasset.

Nesse livro, Ramos abordava a personalidade do mexicano com base em uma perspectiva psicológica, com certa ênfase na problemática questão do complexo de inferioridade. Tratava-se, assim, de um ensaio pioneiro de interpretação da cultura no México. Muito embora integrasse um seleto grupo de intelectuais mexicanos de sua época e apesar de sua condição de discípulo de Antônio Caso, um dos mais importantes filósofos do México naquele momento, Ramos era uma figura de pouca expressão no ambiente filosófico de seu país. Sua relativa projeção no cenário intelectual e filosófico mexicano, alcançada apenas posteriormente, deveu-se muito à divulgação de sua obra por José Gaos.

Depois do contato com o livro de Ramos, Gaos passa a estudar e escrever sobre a obra de vários outros pensadores mexicanos ${ }^{10}$. Tal atividade se inseria no seu projeto de investigar, documentar e escrever a história do pensamento ${ }^{11}$ de língua espanhola, promovendo a elaboração e publicação de trabalhos sobre a história das ideias hispano-americanas. Segundo Gómez-Martínez (1991, p. 61), no fundo, ao reconhecer a existência de um pensamento de língua espanhola, o que Gaos propunha ia muito além de uma tentação patriótica baseada em uma comunidade linguística. Tratava-se de uma nova concepção da filosofia que reconhecia sua própria historicidade. Assim, "a filosofia se apresenta a Gaos, preferencialmente, como um saber histórico, que converte sua filosofia da filosofia em uma história da filosofia, impregnada, como ele

10 Destacam-se, entre outros, Antonio Caso, Alfonso Reyes, Oswaldo Robles, José Vasconcelos, Justino Fernández, Edmundo O'Gorman, Leopoldo Zea. Várias obras de Gaos, dos anos 40 e 50, surgirão desses estudos, bem como de outros sobre autores hispano-americanos não-mexicanos.

11 Horacio Cerutti Guldberg (2003, p. 136) chama a atenção para o fato de Gaos ter delimitado o sentido do termo pensamento, com o propósito de abordar os modos particulares de inserção da prática filosófica na vida sócio cultural da região, refletindo acerca das relações entre filosofia, originalidade e nacionalidade. 
mesmo assinala, de um saber histórico, mas que não pode ser puro saber teórico da filosofia" (Gómez-Martínez, 1991, p. 64).

Num estudo sobre a contribuição metodológica de Gaos para a história das ideias na Hispano-América, Fernández de Amicarelli (1990, p. 26) destaca de que maneira, em Gaos, a história das ideias surge como uma forma cultural de autoafirmação do sujeito latino-americano e como caminho para a filosofia mexicana, em particular, e para a hispanoamericana, em geral. Segundo essa autora, em tal redescoberta da história, a despeito de Gaos ter partido do circunstancialismo de Ortega, "sua interpretação se fundamenta em uma radicalização do historicismo, pela qual a história é recriação do passado e criação do presente e do futuro. Isto é possível graças à mediação e à presença do sujeito no método proposto pelo autor" (Fernández de Amicarelli, 1990, p. 19).

Dessa forma, o propósito de Gaos, dentro de sua concepção relativista e perspectivista da filosofia, era chegar ao conhecimento filosófico hispano-americano não pela via da abstração especulativa, supostamente universalista, mas pela via da sua própria e peculiar história, na direção de um universal concreto, por meio de uma história das ideias. Em termos orteguianos, fazer filosofia era fazer filosofia da própria circunstância (mexicana, hispano-americana), mas sem, entretanto, restringir-se a ela. E para elaborar essa filosofia da própria circunstância era preciso primeiramente reconhecer o pensamento filosófico hispano-americano e seu lugar no processo histórico.

Gómez-Martínez (1991, p. 82) considera que a obra de Gaos representa a transformação do que antes havia sido esporádico, em pensadores isolados, em um programa sistemático a ser realizado coletivamente. Vale saber, um programa com duas frentes: uma história das ideias ibero-americanas e uma filosofia do ibero-americano ${ }^{12}$, que, diversas no início, coincidiriam a partir de 1968 com as tentativas de formulação de um pensamento da libertação no âmbito iberoamericano. Tal programa teria sido condensado e expresso em algumas proposições elaboradas por Gaos, apresentadas num ciclo de jornadas sobre a América Latina promovido pelo Colegio de México, em 1943,

12 Motivados pela orientação de Gaos, vários de seus discípulos mexicanos iriam integrar, a partir de 1949, um grupo filosófico chamado Hiperión (que etimologicamente significa o símbolo da união entre o céu e a terra), que se propunha a discutir os traços distintivos da "mexicanidade" ou da "filosofia do mexicano". Fundado por Leopoldo Zea, o grupo contou ainda com a participação de Emilio Uranga, Ricardo Guerra, Joaquín Sánchez McGregor, Jorge Portilla, Luis Villoro, entre outros. Seus fundamentos foram expressos no texto-manifesto de Zea intitulado La filosofía como compromiso (1949). 
e publicadas no ano seguinte em El pensamiento hispanoamericano (1944). Em linhas gerais, tais proposições prescreviam todo um conjunto de ações e estratégias de organização, institucionalização, articulação, intercâmbio, orientação, fomento, difusão e publicação dos estudos sobre o pensamento de língua espanhola.

Com a sua decisiva contribuição, do ponto de vista organizacional e de incentivo à produção e à difusão de estudos no campo da história das ideias na Hispano-América, ao lado de seu esforço por lançar as bases e os fundamentos teórico-metodológicos que deveriam guiar a nova disciplina, Gaos se tornou a referência pioneira do foco mexicano desse movimento intelectual. Sob a sua orientação, formou-se toda uma geração de discípulos que iria reforçar esse foco de surgimento da história das ideias no México.

\section{O paralelismo do foco argentino e os aportes de Francisco Romero}

A filosofia encontrou um significativo apoio institucional na Argentina, no final do século XIX, com a fundação da Faculdade de Filosofia e Letras da Universidade de Buenos Aires. O propósito inspirador maior era o de formar profissionais no campo da filosofia a partir da promoção de estudos das fontes clássicas, o que resultou no fortalecimento dos estudos filosóficos naquele país. Já nas primeiras décadas do século XX, desse meio surgiram destacadas expressões do pensamento argentino, tais como Rodolfo Rivarola (1857-1942), José Ingenieros (1877-1925), Alejandro Korn (1860-1936), Coriolano Alberini (1886-1960), entre outros.

Com Rodolfo Rivarola inaugurou-se o processo de deslocamento do positivismo então reinante no meio argentino ${ }^{13}$, e sua cátedra de Ética e Metafísica, criada em 1904, marcaria o desenvolvimento posterior do pensamento filosófico em seu país. Na década seguinte, um intelectual de formação eclética, de origem italiana e radicado na Argentina, José Ingenieros (1877-1925), surgiria como um dos principais expoentes do processo de resgate do passado filosófico argentino, com a publicação de Las direcciones filosóficas de la cultura argentina (1914) e o primeiro volume de La evolución de las ideas argentinas (1918). Nessas obras, já se encontrava presente, segundo Roig (1984, p. IV), o postulado alberdiano em defesa da especificidade de uma filosofia americana.

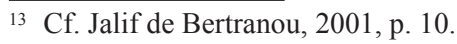


Já nos anos 20, Alejandro Korn foi o nome de maior projeção nesse meio acadêmico argentino, graças, principalmente, à publicação de Nuevas bases (1925) e Filosofía argentina (1927). Assumindo o legado de Alberdi, de quem se considerava herdeiro, Korn se propunha a renovar e revigorar a filosofia argentina, ainda que tal projeto estivesse sob uma grande influência da matriz filosófica alemã, introduzida naqueles meios acadêmicos desde a visita que Ortega y Gasset fez à Argentina em 1916. Para Roig (1984, p. IV), Ingenieros e Korn teriam sido, pela via de um nacionalismo cultural expresso em uma particular apropriação da filosofia positivista, os verdadeiros fundadores da história das ideias na Argentina.

Entretanto, considerando esse mesmo período e comparando-o ao caso mexicano, os estudos filosóficos na Argentina experimentaram algumas diferenças relevantes, sobretudo no que diz respeito à forma e à intensidade com que as teses de Ortega - que tanto influenciaram, de uma maneira geral, no desenvolvimento do pensamento hispanoamericano - foram apropriadas e adaptadas à circunstância nacional da Argentina.

Ortega foi, na Argentina, antes de tudo, um agitador de mentes e o promotor da filosofia acadêmica. Seu pensamento não foi compreendido pelos mestres do momento; tanto Korn como Alberini viram em Ortega o divulgador do pensamento alemão através da Revista de Occidente e dos livros publicados pela biblioteca de Ideias do Século XX. A presença de Ortega deu origem, isso sim, ao estudo sistemático e disciplinado da filosofia europeia. (GómezMartínez, 1991, p. 52).

A mesma opinião é compartilhada por Jalif de Bertranou (2001, p. 10-11), para quem o foco argentino foi menos rico, se comparado ao mexicano, no sentido da elaboração de uma filosofia local, da "argentinidade". Para essa pesquisadora, a primeira visita de Ortega à Argentina, em 1916, teria dado uma nova orientação - germânica à matriz filosófica vigente no país - predominantemente francesa -, embora sua tese do circunstancialismo não tenha provocado o mesmo impacto como no caso mexicano, no sentido de uma "indagação do próprio". Assim, os primeiros esforços para resgatar o passado filosófico na Argentina, desenvolvidos por Ingenieros e Korn, teriam ocorrido paralelamente ao circunstancialismo orteguiano.

De qualquer forma, em que pesem tais diferenças, o legado de Alberdi encontrava-se igual e fortemente presente nos contextos 
filosóficos mexicano e argentino, fato que já demonstra, em certa medida, o desenvolvimento paralelo de uma preocupação filosófica comum a esses países nas primeiras décadas do século $\mathrm{XX}^{14}$. Tal como ocorrera no México, também a Argentina presenciou, nesse período, associado a uma grande intensificação dos seus estudos filosóficos, aquele fenômeno que Ardao (1991, p. XI) chamou de consolidação de uma consciência filosófica latino-americana, consciência essa que buscava valorizar a autorreflexão sobre a produção local, revalorizando-a perante as matrizes filosóficas europeias.

Seguindo a tradição que já vinha se desenvolvendo nas duas décadas anteriores na Faculdade de Filosofia da Universidade de Buenos Aires pelos mestres Ingenieros e Korn, foi o filósofo argentino de origem espanhola Francisco Romero que, a partir da década de 1930, deu continuidade à consolidação de uma consciência filosófica argentina. Ele logo se converteu na principal referência do foco argentino na etapa de fundação do movimento latino-americano de história das ideias. Mais do que propriamente na esfera de sua produção filosófica individual - a propósito bastante significativa ${ }^{15}$, ou na de estudos sobre o pensamento argentino e ibero-americano ${ }^{16}$-, talvez a grande contribuição desse filósofo argentino tenha sido precisamente no campo da articulação, orientação, incentivo e difusão da história das ideias em seu país.

Romero realizou um trabalho que, ao menos nesse sentido e guardadas as devidas proporções, revela certas semelhanças com o que foi desenvolvido por Gaos, no México. Sem contar ainda seus aportes significativos para o debate teórico-metodológico no seio do movimento,

${ }_{14}$ Interessante observar que Ingenieros e Korn, por exemplo, já haviam publicado seus principais estudos no campo do pensamento argentino antes mesmo da chegada de Gaos ao México, em 1938, ou ainda da publicação do livro clássico de Samuel Ramos, em 1934, quando nem sequer se havia constituído o foco mexicano de história das ideias.

15 A posição filosófica de Francisco Romero esteve marcada pela confluência de distintas correntes de pensamento, tais como o historicismo de Ortega (a quem dedicou um estudo publicado em 1960) e Dilthey, a filosofia dos valores de Max Scheler, bem como a fenomenologia, que o levaram a desenvolver o que denominou "filosofia do espírito", na qual ele destaca a sua tese da intencionalidade do psiquismo humano. Em sua ampla produção filosófica mais geral destacam-se as seguintes obras: Filosofía Contemporánea (1941), Filosofia de la persona y otros ensayos de la filosofía (1944), Papeles para una filosofía (1945), Filósofos y Problemas (1947), Filosofía de Ayer y de Hoy (1947), El hombre y la cultura (1950), Teoría del hombre (1952), Qué es filosofía (1953) e Historia de la filosofia moderna (1959).

16 Tais como Alejandro Korn (1940) e Sobre la Filosofía en América (publicado em 1952, mas escrito em 1940). De grande importância foi também a publicação no jornal La Nación de Buenos Aires, em 1940, do seu ensaio intitulado Sobre la filosofía en Iberoamérica, que foi incluído posteriormente no livro Filosofía de la persona (1944). 
particularmente em Estudios de historia de las ideas (1952). Para Zea (1945, p. 1), Francisco Romero "insistiu na necessidade de a IberoAmérica começar a se preocupar com os temas que lhe são próprios, com a exigência de ir até a história de sua cultura e extrair dela os temas de uma nova preocupação filosófica".

Além do relevante trabalho acadêmico que já vinha desenvolvendo na Universidade de Buenos Aires, a contribuição de Romero para a constituição do foco argentino da história das ideias foi decisiva, sobretudo a partir de 1940, quando ele funda, no Colegio Libre de Estudios Superiores, um centro filosófico que denomina Cátedra Alejandro Korn. Nela, Romero daria início a um ousado projeto de produção e publicação de estudos sobre as histórias nacionais da filosofia nos diversos países ibero-americanos ${ }^{17}$.

Tal iniciativa de Romero confirmaria o paralelismo entre os focos argentino e mexicano. Coincidentemente, a fundação da sua Cátedra ocorre exatamente no mesmo ano da fundação do Seminário de José Gaos, no México, ambos com o propósito de difundir a história das ideias e do pensamento filosófico de seus respectivos países e da América Latina em geral ${ }^{18}$. Romero e Gaos abriram, assim, uma nova era na história da filosofia na América Latina, segundo Arturo Ardao, que afirmou ainda:

Não eram senão iniciais os passos que davam então em seus respectivos magistérios americanistas. Nem acordo prévio, nem sequer conhecimento mútuo de propósitos ou de programas. Não obstante, uma consequência notável - para além do condicionamento obrigatório da época - foi o estrito paralelismo de ambos e até a contemporaneidade fundacional no terreno institucional e acadêmico. (Ardao, 1991, p. XII-XIII).

Segundo Ardao (1991, p. XII-XIII), o ano de 1940 representou o momento em que o problema teórico da filosofia americana teria se colocado no primeiro plano como uma preocupação continental,

17 Tal projeto de publicação contou com o apoio da Editorial Losada, de Buenos Aires, e, mais tarde, da Fondo de Cultura Económica. A própósito, Gómez-Martínez (1991, p. 74) traça um interessante panorama da indústria editorial na Ibero-América daquele momento.

18 Cabe destacar aqui a importância fundamental de certos espaços institucionais, como as cátedras de filosofia das universidades do México e de Buenos Aires, além do Colegio de México e do Colegio Libre de Estudios Superiores da Argentina. Locais privilegiados de debate, reflexão, fomento e desenvolvimento de estudos sistemáticos sobre o pensamento e a filosofia ibero-americana, tais espaços se converteram no berço principal do movimento latino-americano de história das ideias. 
ainda que já houvesse uma crescente inquietude pelo passado filosófico hispano-americano. Na verdade, como vimos, antes mesmo de 1940, algumas iniciativas isoladas já expressavam tal inquietude, como é o caso, por exemplo, dos trabalhos do mexicano Samuel Ramos e dos argentinos José Ingenieros e Alejandro Korn, todos publicados nas décadas anteriores. De fato, entre fins do século XIX e o início do XX, a historiografia das ideias, e, dentro delas, em particular, das ideias filosóficas, generalizou-se nos principais centros culturais do continente, numa profunda vinculação com a problemática da identidade nacional (Roig, 1993, p. 14). Entretanto, a crise europeia diante da Segunda Guerra Mundial, com suas consequências no campo das ideias, iria se somar a tais inquietudes, produzindo um terreno fértil para acelerar e unificar definitivamente esse processo de autorreflexão filosófica na esfera da América Latina.

A partir dos anos 40, as iniciativas pioneiras de Gaos e de Romero iriam paulatinamente se integrar num amplo movimento de história das ideias que logo alcançaria uma amplitude continental ${ }^{19}$, não apenas pela ação direta desses dois filósofos, mas, sobretudo, pela ação coordenada de sucessivas gerações de seus discípulos, diretos ou indiretos, espalhados por vários países latino-americanos.

\section{Referências}

ALBERDI, Juan Bautista. Ideas para presidir a la confección del curso de filosofía contemporánea. Montevideo, 1842. Disponível em: <http://www.hacer.org/pdf/Ideas. pdf>. Acesso em: 31 jul. 2006.

ARDAO, Arturo. La filosofía como compromiso de liberación. Cuadernos Americanos. Nueva Época, México, D.F.: Universidad Nacional Autónoma de México, año VI, v. 4 , n. 34, p. 223-249, julio-agosto 1992.

Prólogo. In: ZEA, Leopoldo. La filosofía como compromiso de liberación. [Antología - Selección, cronología e bibliografía: Liliana Weinberg de Magis y Mario Magallón]. Caracas: Biblioteca Ayacucho, 1991. p. IX-XXIX.

CERUTTI GULDBERG, Horacio. Hacia una metodología de la historia de las ideas (filosóficas) en América Latina. 2. ed. México, D.F.: Centro Coordinador y Difusor de Estudios Latinoamericanos, Universidad Nacional Autónoma de México, 1997. 214 p.

19 Entretanto, Roig identifica em Gaos e Romero, respectivamente, a expressão de dois diferentes modos políticos de inserção da história das ideias. No caso de Gaos, a história das ideias se inseria dentro de uma perspectiva nacional e continental, com um forte sentido "hispanizante" e "latino-americanizante", enquanto a perspectiva de Romero se colocava dentro de um "pan-americanismo", que atendia a distintos ideais de unidade continental (alguns inclusive em contradição com as posições políticas de autonomia dos países hispano-americanos). Assim, dessas duas posições iniciais, a de Gaos e daqueles que compartilharam essa mesma linha de pensamento tornaram-se mais fecundas (Roig, 1993, p. 19). 
CERUTTI GULDBERG, Horacio; MAGALLÓN ANAYA, Mario. Historia de las ideas latinoamericanas ¿Disciplina fenecida? México, D.F.: Casa Juan Pablos, Universidad de la Cuidad de México, 2003. 181 p.

DARNTON, Robert. O beijo de lamourette - mídia, cultura e revolução. São Paulo: Cia. das Letras, 1990. 330 p.

FERNÁNDEZ DE AMICARELLI, Estela. José Gaos y la ampliación metodológica en Historia de las Ideas. Cuadernos Americanos. Nueva Época, México, D.F.: Universidad Nacional Autónoma de México, año IV, v. 2, n. 20, p. 19-33, marzo-abril 1990.

GAOS, José. En torno a la filosofía mexicana. México, D.F.: Porrúa y Obregón, 1952. 2 v., 88 e 83 p. 1947.

. Filosofía de la filosofía e historia de la filosofía. México: Editorial Stylo,

. Carta abierta a Leopoldo Zea. In: ZEA, Leopoldo. Filosofar a la altura del hombre. Discrepar para comprender. México, D.F.: Universidad Nacional Autónoma de México, 1993. p. 129-133. [Cuadernos de Cuadernos, 4].

GERBI, Antonello. O Novo Mundo. História de uma polêmica (1750-1900). São Paulo: Companhia das Letras, 1996. 807 p.

GÓMEZ-MARTÍNEZ, José Luis. Una influencia decisiva: el legado de José Gaos al pensamiento iberoamericano. Cuadernos Americanos. Nueva Época. México D.F.: Universidad Nacional Autónoma de México, año V, v. 1, n. 25, p. 49-86, enero-febrero 1991.

JALIF DE BERTRANOU, Clara. Presentación. In: . (comp.) Semillas en el tiempo. El latinoamericanismo filosófico contemporáneo. Mendoza: EDIUNC, 2001. p. 10-15.

ROIG, Arturo Andrés. El pensamiento latinoamericano y su aventura. 2 tomos. Buenos Aires: Centro Editor de América Latina, 1994. 200 p.

. Historia de las ideas, teoría del discurso y pensamiento latinoamericano. Bogotá: Universidad de Santo Tomás - Ediciones USTA, 1993. 201 p. [Reedição de Análisis. Homenaje a Arturo Andrés Roig. Bogotá: Universidad Santo Tomás, v. XXVIII, n. 53-54, 1991].

. La "Historia de las Ideas" cinco lustros después. Estudio introductorio de la edición facsimilar de los números 1 y 2 de la Revista Historia de las Ideas. Colección de Revistas Ecuatorianas. [Editorial Casa de la Cultura Ecuatoriana. Instituto Panamericano de Geografía e Historia. n. 1, Quito, 1959, p. I-XLII] Quito: Banco Central del Ecuador, 1984.

ROMERO, José Luís. Estudios de Historia de las Ideas. Buenos Aires: Losada, 1953. $209 \mathrm{p}$.

SANTAMARÍA GARCÍA, Antonio. El legado filosófico de José Ortega y Gasset en América Latina. José Gaos y el movimiento de Historia de las Ideas. Anuarios de Estudios Americanos, Sevilla: Escuela de Estudios Hispano-Americanos de Sevilla, t. I, n. 2, p. 279-308, 1993.

STROZI, Susana. El discurso del método y el método de los discursos en la historia intelectual de América Latina. In: CANCINO TRONCOSO, Hugo et al. (eds.). Nuevas perspectivas teóricas y metodológicas de la Historia intelectual de América Latina. Madrid: Iberoamericana; Frankfurt am Main: Vervuer, 1999. p. 1-14. 
VILLORO, Luis. Sobre el problema de La filosofia latinoamericana. In: ZEA, Leopoldo. Filosofar a la altura del hombre. Discrepar para comprender. México, D.F.: Universidad Nacional Autónoma de México, 1993. p. 183-201. [Cuadernos de Cuadernos, 4].

ZEA, Leopoldo. A filosofia americana como filosofia. [Tradução: Werner Altmann]. São Paulo: Pensieri, 1993a. 158 p.

. América como Conciencia. 2. ed. México, D.F.: Universidad Nacional Autónoma de México, 1972. Disponível em: <http://www.ensayistas.org/filosofos/ mexico/zea/bibliografia/acc/>. Acesso em: 31 jul. 2006.

. En torno a una filosofía americana. México, D.F.: El Colegio de México, 1945. Disponível em: <http://www.ensayistas.org/antologia/XXA/zea/index.htm>. Acesso em: 31 jul. 2006.

. Filosofar a la altura del hombre. Discrepar para comprender. México, D.F.: Universidad Autónoma de México, 1993b. 391 p. [Cuadernos de Cuadernos, 4].

. José Gaos. Cuadernos Americanos. Nueva Época, México, D.F: Universidad Nacional Autónoma de México, año XIV, v. 1, n. 79, p. 13-57, enero-febrero 2000.

. La filosofía como compromiso de liberación. [Antologia - Selección, cronología e bibliografía: Liliana Weinberg de Magis y Mario Magallón] Caracas: Biblioteca Ayacucho, 1991. 434 p. 